\author{
SANDIA REPORT \\ SAND2007-7085 \\ Unlimited Release \\ Printed November 2007
}

\title{
Hollow Core And Other Infrared Waveguides For Instrumentation In Intense Radiation Environments
}

Jonathan D. Weiss

Prepared by

Sandia National Laboratories

Albuquerque, New Mexico 87185 and Livermore, California 94550

Sandia is a multiprogram laboratory operated by Sandia Corporation, a Lockheed Martin Company, for the United States Department of Energy's

National Nuclear Security Administration under Contract DE-AC04-94AL85000.

Approved for public release; further dissemination unlimited.

Sandia National Laboratories 
Issued by Sandia National Laboratories, operated for the United States Department of Energy by Sandia Corporation.

NOTICE: This report was prepared as an account of work sponsored by an agency of the United States Government. Neither the United States Government, nor any agency thereof, nor any of their employees, nor any of their contractors, subcontractors, or their employees, make any warranty, express or implied, or assume any legal liability or responsibility for the accuracy, completeness, or usefulness of any information, apparatus, product, or process disclosed, or represent that its use would not infringe privately owned rights. Reference herein to any specific commercial product, process, or service by trade name, trademark, manufacturer, or otherwise, does not necessarily constitute or imply its endorsement, recommendation, or favoring by the United States Government, any agency thereof, or any of their contractors or subcontractors. The views and opinions expressed herein do not necessarily state or reflect those of the United States Government, any agency thereof, or any of their contractors.

Printed in the United States of America. This report has been reproduced directly from the best available copy.

Available to DOE and DOE contractors from

U.S. Department of Energy

Office of Scientific and Technical Information

P.O. Box 62

Oak Ridge, TN 37831

Telephone: $\quad$ (865) 576-8401

Facsimile: $\quad$ (865) 576-5728

E-Mail: $\quad$ reports@adonis.osti.gov

Online ordering: http://www.osti.gov/bridge

Available to the public from

U.S. Department of Commerce

National Technical Information Service

5285 Port Royal Rd.

Springfield, VA 22161

Telephone: $\quad$ (800) 553-6847

Facsimile: (703) 605-6900

E-Mail: $\quad$ orders@ntis.fedworld.gov

Online order: $\quad$ http://www.ntis.gov/help/ordermethods.asp?loc=7-4-0\#online

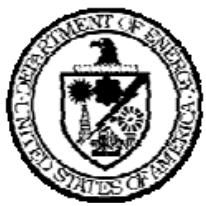


SAND2007-7085

Unlimited Release

Printed November 2007

\title{
Hollow Core and Other Infrared Waveguides For Instrumentation In Intense Radiation Environments
}

\author{
Jonathan D. Weiss \\ Microsystems and Components \\ Sandia National Laboratories \\ P.O. Box 5800 \\ Albuquerque, New Mexico 87185-1081
}

\begin{abstract}
The purpose of this LDRD was to study the effect of steady-state neutron and gamma irradiation on the transmission of waveguides designed to operate well in the near- or mid-IR region of the electromagnetic spectrum. In this context, near-IR refers to the region between $1.3 \mu \mathrm{m}$ and about $2.4 \mu \mathrm{m}$, and mid-IR between $3.0 \mu \mathrm{m}$ and $4.5 \mu \mathrm{m}$. Such radiation environments could exist in nuclear power plants or nuclear weapons. Pulsed and steady-state radiation effects had been extensively studied on silica-based optical fibers because they have been the most readily available, most widely used in communications and sensing, and the least expensive. However, silica-based fibers do not transmit well beyond about $1.8 \mu \mathrm{m}$ and they are virtually opaque in the mid-IR. The mid-IR, as defined above, and beyond, is where vibrational spectroscopy is carried out. This type of sensing is one important application of infrared optical fibers.
\end{abstract}




\section{EXECUTIVE SUMMARY}

The purpose of this LDRD was to study the effect of steady-state neutron and gamma irradiation on the transmission of waveguides designed to operate well in the near- or mid-IR region of the electromagnetic spectrum. In this context, near-IR refers to the region between 1.3 $\mu \mathrm{m}$ and about $2.4 \mu \mathrm{m}$, and mid-IR between $3.0 \mu \mathrm{m}$ and $4.5 \mu \mathrm{m}$. Such radiation environments could exist in nuclear power plants or nuclear weapons. Pulsed and steady-state radiation effects had been extensively studied on silica-based optical fibers because they have been the most readily available, most widely used in communications and sensing, and the least expensive. However, silica-based fibers do not transmit well beyond about $1.8 \mu \mathrm{m}$ and they are virtually opaque in the mid-IR. The mid-IR, as defined above, and beyond, is where vibrational spectroscopy is carried out. This type of sensing is one important application of infrared optical fibers.

This LDRD was an extension of a previous one focused entirely on hollow-core optical waveguides. These are silica tubes that are coated on their inside surface with silver. Silver iodide is added to enhance the reflectivity of silver. Hollow-core waveguides rely on metallic reflection for their operation, rather than total internal reflection at the boundary between the interface between the core and cladding of a conventional optical fiber. It was thought that they should be quite insensitive to radiation because virtually the entire optical path could consist of a tenuous medium, as opposed to glass. However, that supposition would have to be tested because gamma radiation might still cause damage to the reflective coating and neutrons might induce nuclear transmutation in that coating.

Since funding for the earlier LDRD became available near the end of the FY '06, it was known in advance that only planning, purchasing, and designing could be set in motion before the deadline of Sept. 30, 2006. However, an extension was approved during this period to take effect in FY '07, when it was decided to enlarge the study to include other infrared waveguides. However, this extension consisted only of a small amount of funding and even it was cutoff within a few weeks after the start of the new FY. Thus, this report can only consist of a description of the preliminaries required for a complete study.

Despite the limited work possible on this LDRD, it should be noted that a Technical Advance resulted from it. The author of this report was contacted by a small business, known as Controlex, and was asked to collaborate on an SBIR to develop a sensor to detect leaks of the rocket fuel, hydrazine. As result of his contemplation of hollow-core optical waveguides for the LDRD, he proposed a sensor making use of them. This proposal was incorporated into Controlex’s SBIR application.

\section{Work Performed}

Early on, visits were made to the Annular Core Research Reactor (ACRR) and the Gamma Irradiation Facility (GIF) in Area V. This was done to obtain information on the experimental arrangement, radiation characteristics, costs, and scheduling. As a result, it was decided that testing at the GIF would be performed first because of the relative simplicity of doing so.

Purchases were made of the Infrared fibers to be tested. These are: 
1. Hollow-core optical waveguides from Polymicro Technologies.

2. Silica optical fibers from Polymicro Technologies, which served as a kind of reference.

3. ZBLAN (zirconium, barium, lanthanum, aluminum, sodium) fibers from IR Photonics.

4. Silver halide fibers from CeramOptec.

5. Chalcogenide (arsenic and sulfur) fibers from Oxford electronics.

All of these fibers have significantly different transmission characteristics throughout the spectral region of interest.

In addition, IR light emitting diodes were purchased because of their extremely low cost compared to IR lasers, particularly if tunable. In addition, they exist over a wide range of wavelengths. Unfortunately, their optical power output is also low, as is their ability to be focused into a fiber of limited size and numerical aperture. Maximizing their optical power into the fibers was to be of high priority, in preparation for the measurements. These LEDs were purchased from Boston Electronics, a distributor of devices made at the Ioffe Institute in Russia. The various LEDs obtained emit at 1.9, 2.2, 3.0, 3.9, 4.2, 4.7, and $5.4 \mu \mathrm{m}$. In the event that signal levels were too low, the purchase of a $3.39 \mu \mathrm{m}$ helium-neon laser was being considered.

Four infrared detector systems were purchased from Judson Technologies. The detectors themselves were mercury-cadmium-telluride because their response spanned the spectral range of interest. They were cooled by a unit consisting of four thermoelectric coolers in series. The maximum cooling capability was obtained, in anticipation of low signals. In addition, low-noise, trans-impedance amplifiers were included to convert the signals from current to voltage.

In order to focus the light from a fiber on to a detector, which was recessed within the detector housing, calcium fluoride ball lenses were purchased from ISP Optics. These were of diameter: $25 \mathrm{~mm}, 8 \mathrm{~mm}$, and $4 \mathrm{~mm}$. Calcium fluoride exhibits excellent transmission characteristics over the entire spectral range of interest and ball lenses are convenient for the coupling of light from fiber to fiber or detector. A simple optical system for the holding of the lenses, adjustments in position, and coupling of the fiber and detector unit to the system was designed. It was then fabricated by the Sandia machine shop and seemed to work well. Three more were to be fabricated.

\section{Proposed Work}

This work would involve exposing a coil of each type of fiber to the radiation, gammas, in the case of the GIF, or neutrons and gammas, in the case of the ACRR, while simultaneously sending light of a given wavelength through it. If the radiation causes a loss of transmission, the signals will drop in time. It is expected that a steady-state level of radiation-induced absorption will be reached when the rate of recovery will equal the rate at which damage is generated. However, that steady-state level may take an impractically long time to reach if recovery rates are sufficiently slow. In addition, if nuclear transmutation is the cause of transmission loss in the case of hollow-core fibers, recovery will never take place. There is no mechanism of reverse transmutation. Ideally, these tests would be conducted using different wavelengths, since wavelength can affect the radiation response. It does on the case of silica fibers. Clearly, these will be “discovery experiments". However, use will be made of whatever literature may exist on this subject. Ferreting it out is considered part of the proposed work. 


\section{DISTRIBUTION}

$\begin{array}{llll}1 & \text { MS0736 } & \text { D.A. Powers } & 06770 \text { (electronic copy) } \\ 1 & \text { MS1081 } & \text { J.D. Weiss } & 01726 \text { (electronic copy) } \\ 1 & \text { MS9004 } & \text { W.P. Ballard } & 08130 \text { (electronic copy) } \\ & & & \\ 1 & \text { MS0899 } & \text { Technical Library } & 04536 \text { (electronic copy) } \\ 1 & \text { MS0161 } & \text { Patent and Licensing Office } & 11500 \text { (electronic copy) } \\ 1 & \text { MS0123 } & \text { D. Chavez, LDRD Office } & \text { 01011 (electronic copy) }\end{array}$




\section{Sandia National Laboratories}

